\title{
RESEARCH
}

Open Access

\section{Climatic and anthropogenic factors explain the variability of Fagus sylvatica treeline elevation in fifteen mountain groups across the Apennines}

Giuliano Bonanomi ${ }^{1}$, Maurizio Zotti ${ }^{1}$, Valentina Mogavero ${ }^{1}$, Gaspare Cesarano ${ }^{1}$, Luigi Saulino ${ }^{1}$, Angelo Rita ${ }^{1,2}$, Giulio Tesei ${ }^{3}$, Marina Allegrezza ${ }^{3}$, Antonio Saracino $^{1}$ and Emilia Allevato ${ }^{1 *}$ (i)

\begin{abstract}
Background: Fagus sylvatica forms the treeline across the Apennines mountain range, with an average elevation of $1589 \mathrm{~m}$ a.s.l. Previous studies evidenced that the current position of the treeline in the Apennines is heavily depressed as a result of a complex interaction between climatic factors and the past human pressure. In this study we correlated treeline elevation in the fifteen major mountain groups in the Apennines with selected climatic, geomorphological, and human disturbance variables in order to investigate in detail the site-specific features affecting the current treeline distribution.

Results: Treeline elevation was lowest in the North Italy (Apuan Alps), while the highest treeline was found in Central Italy (Simbruini). An absolute maximum treeline elevation of F. sylvatica exceeding $2000 \mathrm{~m}$ a.s.l. was found on 13 mountain peaks in Central and Southern Italy. Noteworthy, treeline elevation was largely lower on warmer south-facing slopes compared to northern slopes, with values several hundred meters lower in the Gran Sasso and Velino-Sirente. Although the causes of this pattern are still unknown, we argue that treeline elevation on southfacing slopes may be limited by the combination of climatic constraints (i.e. summer drought) and human disturbance. Evidence of a pervasive anthropogenic effect depressing treeline elevation was found in the North (Apuan Alps) Central (Gran Sasso, Velino-Sirente, Sibillini) and Southern part of Apennines (Pollino). By contrast, treeline elevation of the Laga, Simbruini, and Orsomarso mountain groups appears less affected by past anthropogenic disturbance. Finally, we recorded in the several mountain groups (i.e. Majella, Marsicani and Pollino) the coexistence of very depressed treelines just a few kilometers away from much higher treelines, among the highest ever recorded for F. sylvatica.
\end{abstract}

Conclusions: Finally, we argue that F. sylvatica treeline across the Apennines is locally shaped both by the interaction of low temperatures experienced by the species in its earliest life stages in snow-free open spaces with summer soil water depletion and human disturbance.

Keywords: Anthropogenic impact, Latitudinal gradient, Mean annual temperature, Population density, Summer drought, Winter temperature

\footnotetext{
*Correspondence: eallevat@unina.it

'Dipartimento di Agraria, Università di Napoli Federico II, via Università 100,

80055 Portici, NA, Italy

Full list of author information is available at the end of the article
} 


\section{Introduction}

The treeline is a well identifiable ecological boundary representing the upper ecological limit for forest growth and development. Treelines range worldwide from a few meters above sea level in high latitudinal regions to more than $\sim 4000 \mathrm{~m}$ a.s.l. in the Himalayan mountain range and in the Andean Cordilleras (Körner 1998).

In recent decades, several studies have sought to shed light on the physiological and ecological factors affecting treeline altitude at regional and global scales (Harsch et al. 2009; Wang et al. 2017). It is widely agreed that temperature is the most important limiting factor for tree growth and development at high altitude (Körner and Paulsen 2004). Limiting temperature, however, at local scale interacts with mountain topography, soil quality, and biotic factors like herbivores and anthropogenic disturbance that may substantially change treeline shape and elevation (Macias-Fauria and Johnson 2013; Ameztegui et al. 2016). In this regard, several studies have shown that drought, recurrent fire and logging can dramatically depress treeline elevation compared to the species potential based on climatic stress alone (Piper et al. 2016; Bonanomi et al. 2018). For instance, aspect controls the amount of solar radiation reaching surfaces (Monteith and Unsworth 2013), thus affecting air, soil and vegetation temperatures (Wieser and Tausz 2007). As a consequence, at mid-latitudes in the Northern Hemisphere, south-facing slopes receive much more direct solar radiation than comparable northern slopes. Thus treeline elevation is expected to be higher on south-facing warmer slopes than on their cooler northfacing counterparts. However, in the Mediterranean area, which is frequently subjected to drought and soil moisture depletion in the summer season, south-facing slopes can be more prone to drought than north-facing slopes, causing a substantial lowering of treeline elevation (Piper et al. 2016; Bonanomi et al. 2018).

Most previous research aimed at identifying the environmental factors controlling treeline elevation, studied natural sites with limited disturbance, discarding areas affected by human activities (Körner and Paulsen 2004). However, this approach yields few insights into the current treeline position which is the net interaction between ecological factors and past and present human activities. This especially holds in densely inhabited inland areas, as found in Western Europe and the Mediterranean basin: several studies carried out in the Alps, the Pyrenees as well as the Apennines indicate a significant lowering of actual treeline elevation caused by past human activity in terms of fire, grazing and logging, creating secondary grassland in place of high elevation mountain forests (Pignatti 1998; Tinner et al. 1996; McNeill 2002).

Worldwide, the treeline is commonly formed by evergreen conifer species in mountains of boreal and temperate regions (Körner 2012), with broadleaf evergreen species dominant in tropical latitudes with less accentuated seasonal extremes (Jobbágy and Jackson 2000). Instead, much less common are treelines formed by broadleaf deciduous species. Notable exceptions are treelines formed by Nothofagus species in South America, and by Fagus sylvatica in the Mediterranean basin (Körner and Paulsen 2004). F. sylvatica is a highly competitive species which maintains a high growth rate up to late maturity, with limited tolerance to drought and to spring frosts (Nolè et al. 2018; Allevato et al. 2019) which may seriously damage new inflorescences and leaves, thereby limiting distribution of the species in a continental climate (Larcher 1980; Packham et al. 2012). Although F. sylvatica is present at sea level in Northern Europe and Scandinavia (Randin et al. 2013), in the Apennines mountain range this species dominates the vegetation belt from 800 ma.s.l. up to the treeline, mixed with Abies alba only in more thermophilous low-elevation Mediterranean beech forests (Di Pasquale et al. 2014; Rita et al. 2014). Recently, in a study on F. sylvatica treeline elevation in the Apennines, Bonanomi et al. (2018) reported an average elevation of 1589 m a.s.l., with considerable variability among peaks ranging from less than $1000 \mathrm{~m}$ a.s.l. to the highest site reaching $2141 \mathrm{~m}$ a.s.l. This study, however, did not investigate the variability of treeline elevation within different mountain groups forming the Apennines. In this regard, several attempts have been made to identify specific features of treelines in different mountain groups, including the Northern Apennines (Pezzi et al. 2008), the Majella (Palombo et al. 2013), the Sibillini (Vitali et al. 2018), as well Gran Sasso and Laga (Mancini et al. 2016). However, to date no studies have made a systematic comparison of current treeline distribution across different mountain groups in the Apennines.

To fill this gap, we first determined current treeline distribution in the fifteen major mountain groups in the Apennines, thus providing an unbiased data set. We then compared treeline elevation in different mountain groups with special attention to the differences associated with slope aspect. Finally, we analysed the relationships between treeline distribution with selected climatic, geomorphological, and human disturbance variables to explore the factors that affect $F$. sylvatica treeline distribution. We tested the following hypotheses: (i) the treeline is higher in the cooler northern aspect compared to the warmer southern sides; (ii) mountain groups surrounded by populous areas have more depressed treelines; (iii) and treeline elevation is more variable in mountain groups which are more subject to human pressure.

\section{Materials and methods}

\section{Study area}

The Apennines is a $\sim 1200 \mathrm{~km}$-long mountain range, running like a backbone down the Italian peninsula from 
north to south, ranging in latitude from $38^{\circ} \mathrm{N}$ to $44^{\circ} \mathrm{N}$. The Apennines include 261 major and secondary peaks above $2000 \mathrm{~m}$ a.s.l., with the highest point at the Gran Sasso (2912 m a.s.l.). The Apennine substrate mainly consists of limestone, with occasional arenaceous-pelitic flysch in Northern and Central Italy.

F. sylvatica is the most common species in the mountain belt between $\sim 800 \mathrm{~m}$ a.s.l. up to the treeline. Almost monospecific stands of $F$. sylvatica are recorded at the treeline (Hofmann 1991; Piovesan et al. 2005), coexisting with relict conifer species only at a few locations. For instance, Picea abies can be found in the northern Apennines (Magini 1972), while Pinus heldreichii subsp. leucodermis forms treelines in the southern Apennines in the Pollino group (Todaro et al. 2007).

For the purpose of this work, we specifically selected only mountains peaks with an elevation above $1500 \mathrm{~m}$ a.s.l. since few of the mountains below this elevation show evidence of a treeline. For our purposes, the mountain peaks of the Apennines were clustered into 15 main groups based on a well-recognized geographical criterion (Almagià 1959). Specifically, the following mountain groups were identified from the northern to southern Apennines: the Apuan Alps, Tosco-Emiliano, Sibillini, Laga, Terminillo, Gran Sasso, Velino-Sirente, Majella, Simbruini, Marsicani, Matese, Picentini, Alburni-Cervati, Pollino, and Orsomarso (Fig. 1).

\section{Treeline altitude assessment}

To determine the current $F$. sylvatica treeline elevation we used a recently published data set (Bonanomi et al. 2018). Briefly, the Apennines treeline position was mapped on Google Earth Pro ${ }^{\text {max }}$ (Google Inc., Mountain View, CA, USA), using the time series images ranging from 2004 to 2011, with which the treeline boundaries of all Apennine mountain peaks were digitized, amounting to a total of 302 mountains. Here, the data set was restricted to mountain peaks belonging to the same selected geographical group and excluding isolated mountains (Additional file 2: Table S1). The present data set include 224 peaks that, in fact, include all peaks within each mountain groups. For each peak $(N=224)$ the whole treeline i.e. the boundary lines that connect the highest patches of forest, were identified and digitalized

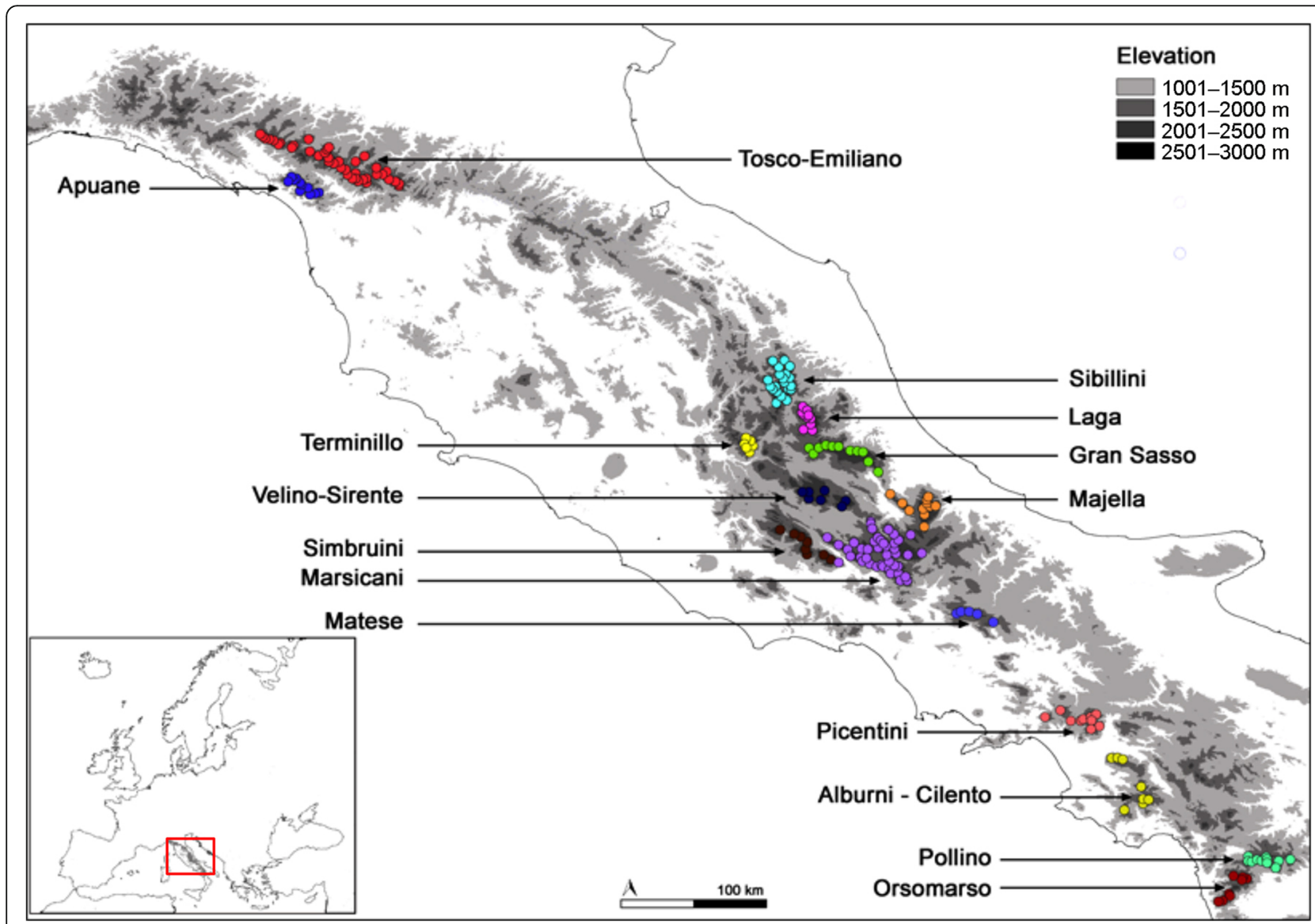

Fig. 1 The 15 selected Apennines mountain groups, indicated with different color dots, where Fagus sylvatica treeline elevation was measured in all the mountain peaks belonging to each group. Overall, 224 mountain peaks were included in the study 
to measure the maximum, minimum and average elevation. This analysis was carried out on the four aspects of each mountain peak, thus providing the complete assessment of treeline elevation for each peak.

Treeline position was mapped with accuracy of the Google Earth-measured points. The accuracy of the Google Earth-measured data was checked by field measurements on 80 peaks distributed along the whole Apennines, corresponding to $35.7 \%$ of geolocated waypoints, with a Garmin Montana 600 GPS device equipped with a barometric altimeter. Overall, we found a negligible deviation among Google Earth and GPS measurement, being in average of +0.3 and $-0.2 \mathrm{~m}$ for lowest and highest treeline points, respectively (Bonanomi et al. 2018).

\section{Variables associated with the treeline}

In a previous study (Bonanomi et al. 2018) we analysed the explanatory capability of 58 variables to predict treeline distribution across the Apennines. Here, based on the previous work, we selected the 13 variables most closely correlated with treeline elevation across the entire mountain chain to assess their capability to explain the difference observed among the 15 mountain groups. The variables were grouped into three classes: climatic, geographical and topographical, and anthropogenic variables (Table 1$)$.

With regard to climatic variables, mean annual temperature (MAT), mean temperature of warmest

Table 1 Variables considered in the analysis of Fagus sy/vatica treeline elevation in different mountain groups within the Apennines

\begin{tabular}{lll}
\hline Variable & Unit & Symbol \\
\hline $\begin{array}{l}\text { Geographic \& topographic } \\
\text { Peak elevation }\end{array}$ & m a.s.l. & PE \\
Latitude & degree & LAT \\
Distance from the sea & $\mathrm{km}$ & $\mathrm{SD}$ \\
Aspect & ${ }^{\circ}$ & $\mathrm{A}$ \\
Slope & $\%$ & SLP \\
Climatic & & \\
Mean annual temperature & ${ }^{\circ} \mathrm{C}$ & MAT \\
Mean temperature of warmest month & ${ }^{\circ} \mathrm{C}$ & MTWM \\
Mean temperature of coldest month & ${ }^{\circ} \mathrm{C}$ & MTCM \\
Mean temperature of warmest quarter & ${ }^{\circ} \mathrm{C}$ & MTWQ \\
Mean temperature of coldest quarter & ${ }^{\circ} \mathrm{C}$ & MTCQ \\
Annual precipitation & $\mathrm{mm} \cdot \mathrm{y}^{-1}$ & AP
\end{tabular}

Demographic

Population density within a $10.0 \mathrm{~km}$ radius around $\mathrm{n} \cdot \mathrm{km}^{-2}$ HP 1860 each mountain peak at three time points (1860,

1921, and 2011)

HP 1921

HP 2011 month (MTWM), mean temperature of coldest month (MTCM), mean temperature of the warmest quarter (MTWQ), mean temperature of the coldest quarter (MTCQ), and Annual Precipitation(AP) were selected.

Data were extracted from the global climate database WorldClim 2.0 (http://www.worldclim.org; Hijmans et al. 2005) at a spatial scale resolution of $1 \mathrm{~km}^{2}$. In the WorldClim database, the temperature is calculated as the spatial average of grid squares that include the selected point and adjusted according to their average elevation. Data were then normalized, following the method of Jobbágy and Jackson (2000), to remove the effect of the elevation of individual grid squares by reporting the temperature at sea level for each mountain peak by a $0.006^{\circ} \mathrm{C} \cdot \mathrm{m}^{-1}$ adiabatic lapse rate (Barry 2008). For cumulative annual rainfall, data were collected from the Bioclimates of Italy because of the higher spatial resolution compared with WorldClim for the Apennines. In brief, these rainfall data were obtained with a calibration process, via regression kriging, of the WorldClim (1.4), with a large data set from local meteorological stations (Pesaresi et al. 2017).

With regard to geographical and topographical variables, most of the selected mountain groups share similar bedrock (i.e. limestone), with the exception of the Tosco-Emiliano and Laga groups that have arenaceouspelitic flysch substrata (Additional file 2: Table S1). Data for bedrock type were obtained from the maps of the National Cartographic Portal of Italy (www.pcn.minam biente.it/GN). Additional geographical information concerning treeline position i.e. peak elevation (PE), latitude (LAT), distance from the sea (SD), aspect (A), and slope (SLP) was also included in the dataset (Table 1).

Finally, human impact was indirectly quantified using population density around each mountain peak as a proxy. Specifically, we used the population within a 10$\mathrm{km}$ radius around each mountain peak in three dates: 1860, 1921, and 2011 (named HP1860, HP1921, and HP2011, respectively). This variable was selected because a very detailed census of human population is available in Italy at very fine resolution (7998 municipalities with $\sim 10$ years resolution for the last 150 years, www.istat.it). Other parameters that could be a good proxy for human impact such as the amount of wood removed by cutting, the stock of grazing animals (cow, sheep, goat, etc.), and road network were not consider in this study because their distribution are very sparse in time and space.

\section{Data analysis}

For each mountain group, maximum, minimum and average values of treeline elevation (TLE) were calculated. The number of mountain peaks differed for each mountain group as follows: Apuan Alps (11), ToscoEmiliano (40), Sibillini (24), Laga (11), Terminillo (9), 
Gran Sasso (11), Velino-Sirente (7), Majella (11), Simbruini (8), Marsicani (48), Matese (5), Picentini (10), Alburni-Cervati (8), Pollino (12), and Orsomarso (9).

The role played by aspect in treeline elevation was analysed by focusing on northern and southern mountain faces. For each mountain group we calculated the differences between north and south average treeline elevation ( $\Delta$ average TLE north - average TLE south) and between north and south maximum elevation $(\Delta$ maximum TLE north - south). Finally, for each mountain group we calculated the difference between the maximum treeline elevations recorded within the group and the average values of the same group ( $\Delta$ maximum TLE - average TLE). The significance of the index is to quantify the depression of the treeline compared to the maximum values recorded within each homogeneous mountain group.

In order to increase explicative power of multivariate analysis, hierarchical clustering of the 13 geographical, demographic and climatic variables were performed on average values for each Apennine chains. Prior to clustering analysis, values for each variable are normalized through mean subtraction and divided by their standard deviation in order to avoid biases from scale disparities of the variables. It then makes it possible to derive meaningful distances between samples, using Euclidean distance. Results of Euclidean distance resemblance matrix were plotted in dendrogram.

The same pre-treatment and multivariate analytical approach were performed for dataset generated from treeline elevation (TLE) variables (average TLE, maximum TLE, minimum TLE, $\Delta$ average TLE north average TLE south aspects and $\Delta$ maximum TLE - average TLE). Additionally, the normalized dataset generated from treeline variables were stressed in Principal component analysis (PCA), in order to visualize specific association between Apennine mountain groups and TLE attributes. To further emphasize the common relation between TLE and mountain groups clustering calculated on Euclidean distance are overlaid in loading plots diagram. Similarity profile tests (SIMPROF) were applied as multivariate permutational test (number of permutation: 999) to each normalized datasets to obtain significant clustering among mountain groups. Dendrograms, PCA of TLE data and SIMPROF tests were generated in Primer-v7 (Clarke and Gorley 2015).

A further multivariate approach by using principal component analysis (PCA) was performed to assess how the intrinsic variation in the 13 selected geographical, climatic and demographic variables explain treeline elevation (i.e. minimum, average and maximum) in each mountain peak belonging to different mountain groups. In order to assess the association between the 13 variables and the treeline elevation, we followed the approach suggested by Legendre and Legendre (2012) for supplementary variables. We plotted treeline elevation values as loading vectors on bi-dimensional PCA space even if it was not used to compute the eigenvalues of the same ordination space and do not contribute to the specific ordination of mountain peaks in score plot.

\section{Results}

In all, $2895 \mathrm{~km}$ of treeline on 224 mountain peaks were measured for this study. The absolute maximum treeline elevation ranged between 1687 in the Apuan Alps to $2141 \mathrm{~m}$ a.s.l. in the Pollino massif (Fig. 2). Absolute maximum treeline elevations exceeding $2000 \mathrm{~m}$ a.s.l. were found on 13 mountain peaks, namely five on Pollino, five also on the Majella, and three in the Marsicani group.

As regards the average treeline elevation, the lowest value of $1286 \mathrm{~m}$ a.s.l. was found in the Apuan Alps, while the highest was $1752 \mathrm{~m}$ a.s.l. in the Simbruini. High values were recorded also in Laga, Orsomarso, Pollino and Terminillo (Fig. 2). By contrast, very low average treeline elevations were recorded in the Sibillini, Gran Sasso, Velino-Sirente, and Matese. The current analysis revealed that aspect greatly affected treeline elevation. Treeline elevation was higher in northern aspects compared to southern in all mountain groups, with south-facing treelines across the Apennines, on average, $127 \mathrm{~m}$ lower (Fig. 3a, b). We found very high values of $\Delta$ average TLE north - south in the Velino-Sirente, Matese, Apuan Alps and Gran Sasso with, instead, low values in the Tosco-Emiliano, Orsomarso, Picentini and especially Terminillo groups.

Interestingly, we found $\Delta$ maximum TLE north maximum TLE south very close to zero in Majella, Picentini and Velino-Sirente, with slightly negative values in Orsomarso, Tosco-Emiliano and Sibillini (Fig. 3c, d). By contrast, $\Delta$ maximum TLE north - maximum TLE south attained very high values for Simbruini, Pollino and especially Gran Sasso. Finally, the $\Delta$ maximum TLE - average TLE (i.e. the differences between absolute maximum elevation minus the average treeline elevation) was very high for Pollino, the Apuan Alps, Majella and Gran Sasso, with the lowest values recorded in Laga (Fig. 4).

The hierarchical clustering of the fifteen mountain groups based on the geographical, demographic and climatic variables shows significant differences between mountain groups and are showed in dendrogram (Additional file 1: Figure S1). The most distant mountain group is Apuane, forming single cluster at Euclidean Distance (ED) value of 8.15 , with respect to all the other mountain groups $(p<0.001)$. At 5.05 ED value two internal clusters are formed $(p<0.001)$ including a first group formed by Orsomarso, Pollino, Picentini, AlburniCilento and Matese and a second composed by the 


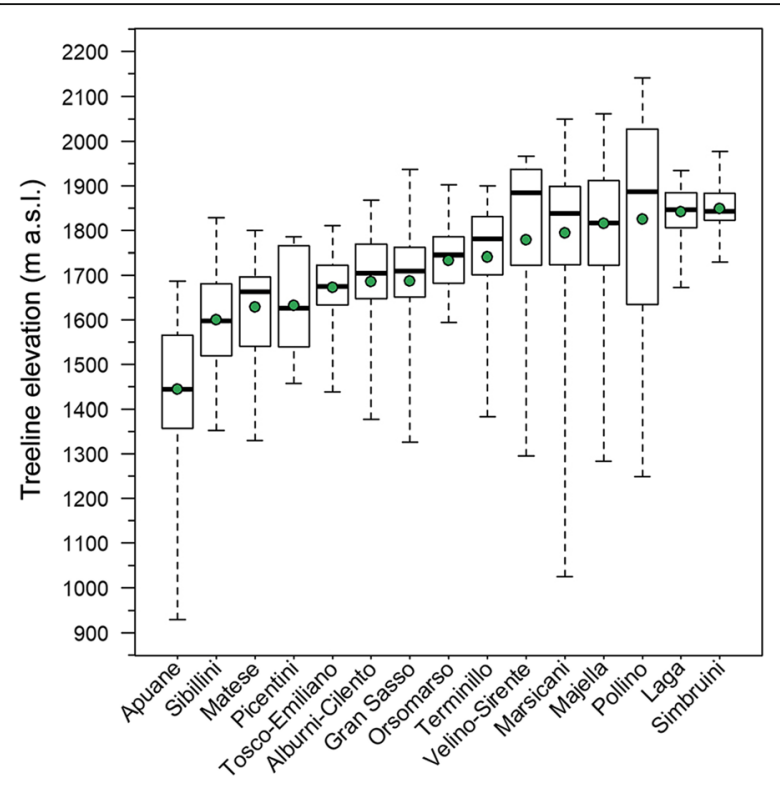

Fig. 2 Distribution of the maximum treeline elevation of Fagus sylvatica measured in all the mountain peaks $(N=224)$ of the 15 selected Apennine mountain groups. The top and bottom edges of the box are the 1st and 3rd quartiles, respectively; above and below bars indicate maximum and minimum values, respectively; the central line indicates the median value; green circles indicate the average value

remaining mountain groups. Notably, in the second group an additional cluster node is formed by ToscoEmiliano mountain group and the others at ED of 4.77 $(p=0.002)$. Internally to the first and the second groups other less significant clustering take place and are showed in Additional file 1: Figure S1.

Principal component analysis (PCA) of mountain groups based on TLE parameters explains overall $99.5 \%$ of the total variance in the dataset (PCI: $76.4 \%$ and PCII: $23.1 \%$ ) and is used in combination with ED clustering of the mountain groups (Fig. 5a and b). In detail, multivariate data analysis showed that Velino-Sirente mountain group forms single cluster at ED of $0.22(p<0.001)$, this clustering mainly caused by higher level of positive association with $\Delta$ average TLE in north and south aspects and negative association with $\Delta$ maximum TLE - average TLE. A second clustering occurs at 0.16 ED value at significance level of $p(0.001)$, leading to the formation of a distinct group characterized by level of Euclidean distance below $0.08(p=0.32)$. This last cluster, containing Apuane, Matese, Gran Sasso and Majella, is mainly due to positive association with maximum TLE values and negative association with the minimum TLE values.

Conversely, the other cluster forms two subordinate clusters at $0.10 \mathrm{ED}$ with single cluster composed by Orsomarso and the other cluster containing all the other mountain groups. Segregation of Orsomarso is given by the strong positive association with minimum TLE and negative association with maximum TLE. The other mountain groups, namely Pollino, Marsicani, ToscoEmiliano, Alburni-Cilento, Laga, Simbruini, Sibillini, Picentini, and Terminillo are clustered by a slight positive association with minimum TLE and $\Delta$ maximum TLE - average TLE. Further, sub-clustering at 0.06 ED and corresponding significance levels are showed in Fig. 5.

The Principal component analysis (PCA) based on 13 variables provided a satisfactory ordination of the treeline elevation across the 15 mountain groups, with the first two eigenvalues accounting for $62.04 \%$ (40.31\% and $21.73 \%$, respectively for the first and second components) of the total variance. In Fig. 6 we report the loading vector variables (i.e. for each parameter value actually recorded, and how they relate to the PC axes), in bi-dimensional space. The first PCA component highlights the importance of mean annual temperature (MAT), minimum temperature of the coldest month (MTCM), and latitude, although the last variable had the opposite effect. The second PCA component indicates the importance of human population which is negatively associated to minimum, average and maximum treeline elevations in most of the mountain groups (Fig. 6). PCA also revealed a large variability within the ToscoEmiliano, Gran Sasso, and Marsicani groups, with more homogeneous conditions within Orsomarso, Picentini and the Apuan Alps. Treeline elevation in the Apuan Alps is strongly and negatively associated with population, which also affects Tosco-Emiliano, albeit, in the latter case, with a substantial contribution of latitude. Settlements around mountains explain a large variability also for Gran Sasso, Majella, Velino-Sirente and Marsicani with a minor role, instead, for Orsomarso. Treeline elevation of Orsomarso and Pollino was associated with MAT, MTCM and with a contribution of MTCQ. Finally, topographical variables had no great influence, although latitude (LAT) played an important role in the distribution of the treelines of the Picentini in concomitance with annual precipitation (AP).

\section{Discussion}

This study revealed a large variability of $F$. sylvatica treeline elevation among as well as within the 15 mountain groups analysed. Our survey revealed that treeline elevation is the results of both climatic factors and anthropogenic disturbance that play a different role across the Apennine mountain range. First, we recorded a remarkable depression of treeline elevation in all mountain groups compared with the expected climatic potential, suggesting a pervasive anthropogenic effect. Moreover, we found that treeline elevation was consistently lower on warmer, south-facing slopes of all mountain groups 


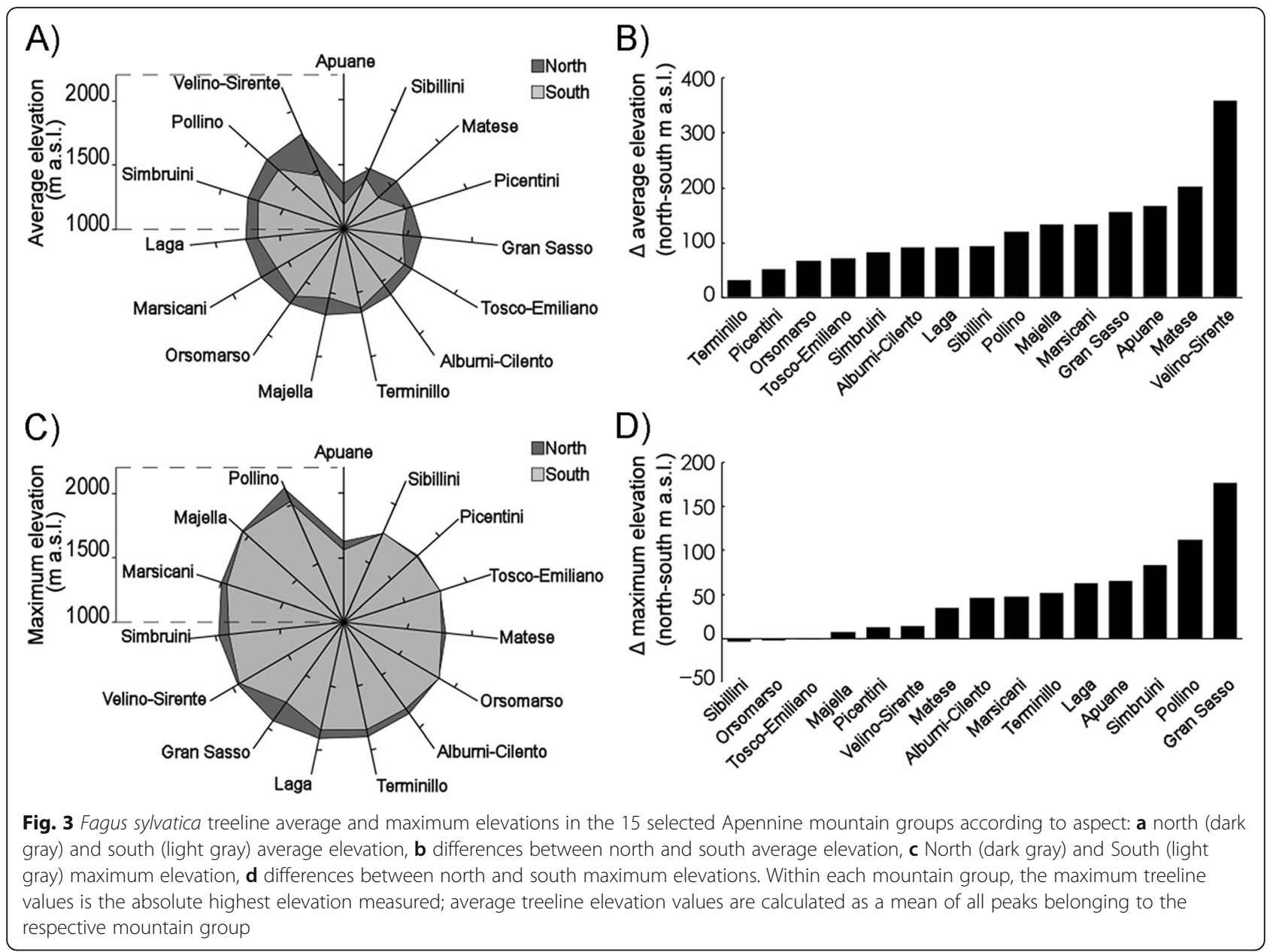

analysed. This pattern, although still not explained, could be associated to a synergic interaction between climatic constraints (e.g. summer drought) and human disturbance (e.g. logging and grazing pressure) that may leads to the loss F. sylvatica canopy viability and of their regeneration capability. According to our hypothesis, we found within mountain groups the coexistence of a very depressed treeline, in several cases with elevation of $1000 \mathrm{~m}$ a.s.l., with very high treeline placed well above $2000 \mathrm{~m}$ a.s.l. The co-occurrences of such variability in

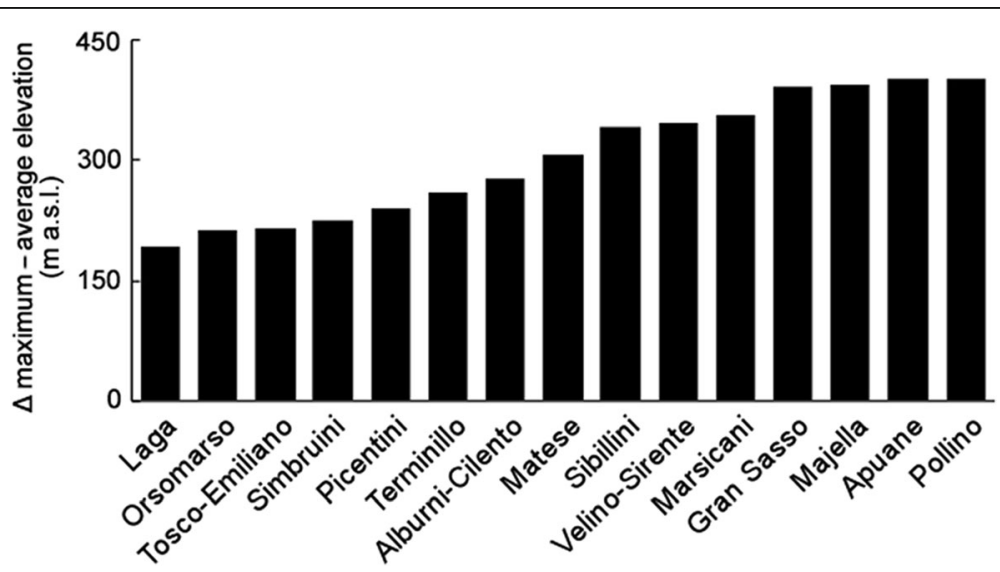

Fig. $4 \Delta$ maximum - average treeline elevation (differences between absolute maximum elevation and the average treeline elevation) for Fagus sylvatica treeline in 15 selected Apennine mountain groups 


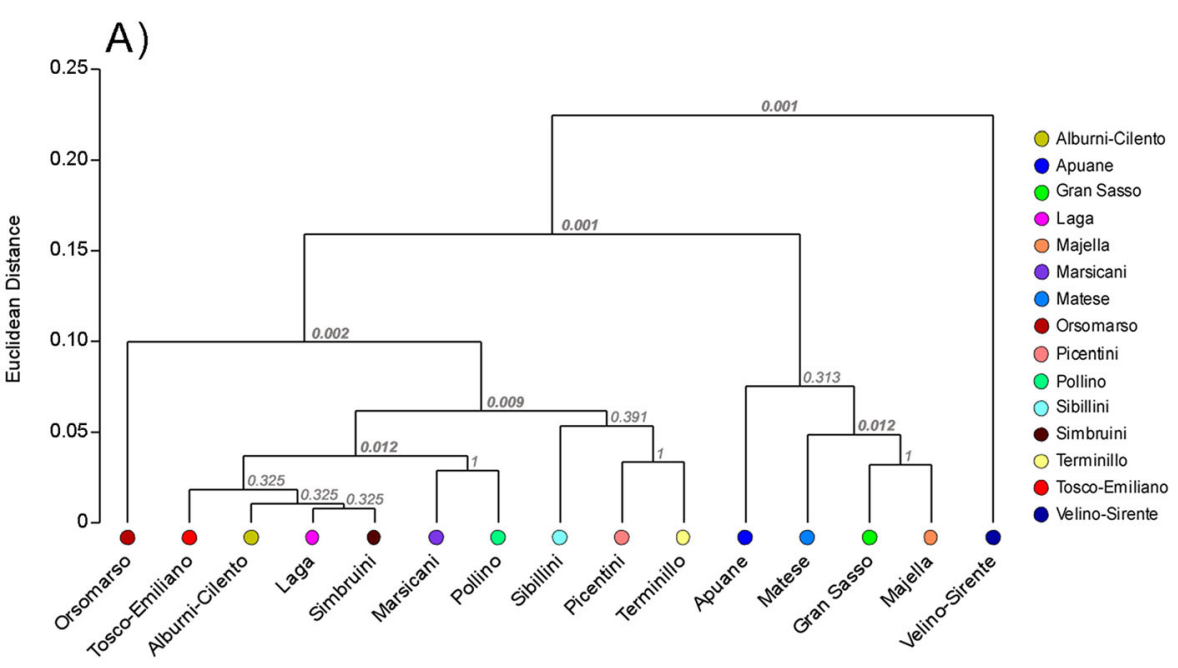

B)

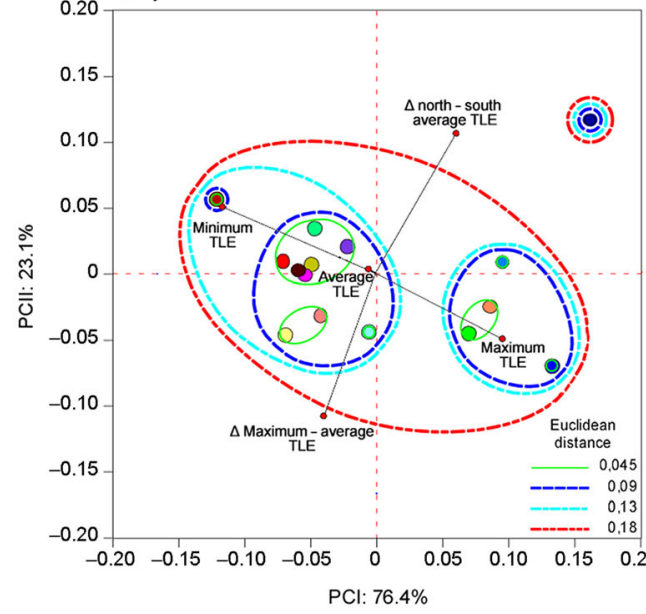

C)

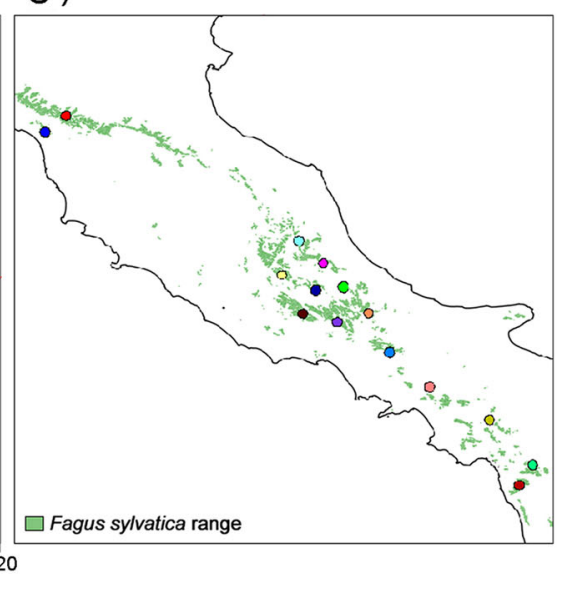

Fig. 5 Comparative multivariate data analysis among mountain groups. Panel a shows hierarchical ordination of Apennine mountain groups according to Euclidean distance calculated on treeline elevation (TLE): maximum TLE, minimum TLE, average TLE, $\Delta$ average TLE north aspect average TLE south aspect, $\Delta$ maximum TLE - average TLE variables. Grey numbers in correspondence of the nodes report $p$ value, in bold significant differences. Panel $\mathbf{b}$ shows specific association of treeline attributes with Apennine mountain groups, clustering of mountain groups is performed through overlay function of Euclidean distance. Panel $\mathbf{c}$ shows the geographical distribution of the fifteen selected mountain groups throughout the Apennine Fagus sylvatica range

treeline elevation is sites that are few kilometres apart suggest that factors other than climate control this pattern. In this context, we argue that high elevation treeline exist in very remote and inaccessible suspended valleys that protected it from past and present anthropogenic disturbance. On the other hands, very depressed treeline are located in accessible areas that was extensively exploited in the past centuries. Hereafter, we discuss the treeline patterns and the potential causative factors for each of the 15 mountain groups analysed.

\section{Northern Apennines}

Apuan Alps had the lowest average treeline in Italy (814 $\mathrm{m}$ a.s.l.), lower than the adjacent Tosco-Emiliano. Moreover, the Apuan Alps have a very high value of $\Delta$
Maximum TLE - Average TLE, which indicate that the treeline could potentially reach high elevations, but the average values are heavily depressed. The Apuan Alps and the Tosco-Emiliano group are situated at a similar latitude and share a similar climate, with very high rainfall and a limited summer drought (Fratianni and Acquaotta 2017). The most striking feature of the Apuan Alps which may explain the depressed treeline is the very high population density around this mountain group, with several large towns (e.g. Massa Carrara, Viareggio) situated a few kilometers from the main peaks. As early as 1861 , the human population numbered $\sim 83,000$ and $\sim 88,000$ around Mt. Pisanino and Punta Carina, respectively, two of the most important peaks in this group. More importantly, the mountain 


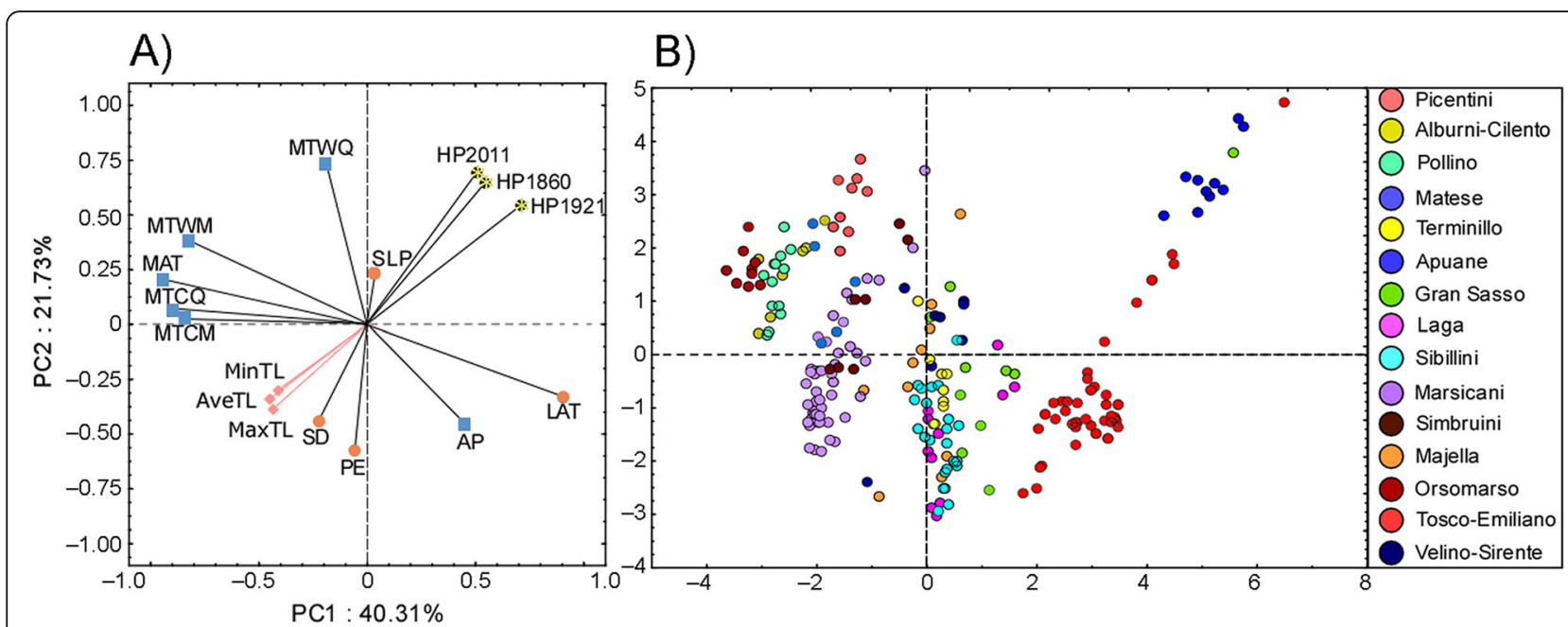

Fig. 6 Principal Component Analysis (PCA). Loading plots of 15 selected Fagus sylvatica treeline elevations according to: a topographic, anthropogenic and climatic variables and $\mathbf{b}$ relative Score plots Segregation variables according to relative loading plots. For topographic and geographic variables acronyms are: peak elevation (PE), distance from the sea (SD), latitude (LAT) and slope (SLP); for climatic variables: mean annual temperature (MAT), mean temperature of warmest month (MTWM), mean temperature of coldest month (MTCM), mean temperature of warmest quarter (MTWQ), mean temperature of coldest quarter (MTCQ) and annual precipitation (AP). For anthropogenic variables: population density at $10.0 \mathrm{~km}$ radius around each mountain peak in the year 1860 (HP1860), 1921 (HP1921), and 2011 (HP2011). Minimum treeline elevation (MinTL), Average treeline elevation (AveTL) and Maximum treeline elevation (MaxTL) were also plotted as supplementary variables (red vectors) following Legendre and Legendre (2012)

group was intensively exploited in pre-Roman times (Bruschi et al. 2004) and in recent centuries for its marble deposits (Carmignani et al. 2007), causing a dramatic change in mountain morphology and hence the complete removal of forest cover on several peaks. PCA analysis confirmed that past and present human population density is the most important explanatory variable for the low treeline elevation in this mountain group.

The Tosco-Emiliano group has a higher treeline elevation than the Apuan Alps, despite the similar climate and latitude. Moreover, it has low values of both $\Delta$ average TLE north - average TLE south and of $\Delta$ maximum TLE - average TLE, suggesting that it has been subject to more limited human disturbance compared to the nearby Apuan Alps. Therefore, the highest treeline, recorded at $1811 \mathrm{~m}$ a.s.l. in the Monte Prado peak (2054 m a.s.l.), probably reflects climatic limitations (Pezzi et al. 2008), the group lying at the boundary of the Northern Apennines and thus experiencing much colder weather conditions compared to mountain groups in the Central and Southern Apennines. Finally, PCA analysis indicates that rainfall affects treeline elevation in this group, which is indeed the wettest in the Apennines. In this regard a weak but positive correlation between treeline elevations across the Apennines with the amount of summer precipitation was documented (Bonanomi et al. 2018). Here we speculate that high rainfall can alleviate summer drought, especially in southern aspects, contributing to the presence of a high elevation treeline also on the southern slopes of these mountains.

\section{Central Apennines}

The Apennines in central Italy comprise nine main mountain groups, namely the Sibillini, Laga, Gran Sasso, Terminillo, Majella, Velino-Sirente, Simbruini, Marsicani, and Matese. Blasi (2010) placed the potential elevation limit of F. sylvatica in central Italy at $1900 \mathrm{~m}$ a.s.l. However, we found eight sites where the treeline elevation exceeded $2000 \mathrm{~m}$ a.s.l. (five in the Majella and three in the Marsicani group). The existence of several sites located well above the threshold of $2000 \mathrm{~m}$ a.s.l. clearly demonstrate that the climatic potential of $F$. sylvatica is much higher than previously thought (Blasi 2010). Currently, we focusing on these study sites to better define the upper climatic limitation of $F$. sylvatica in areas subject to minimal anthropogenic disturbance. The discovery of very high treeline, most of which are located in remote and inaccessible valleys, highlight the general and widespread treeline depression of Central Apennines. In fact, in all mountain groups analysed the average treeline elevation occurs several hundred meters below its potential climatic limit.

Sibillini had the lowest average treeline in central Italy (1202 $\mathrm{m}$ a.sl.), with also a relatively low absolute maximum (1828 m a.s.l.). This mountain group is characterized by very ample and characteristic altitudinal grasslands (Catorci et al. 2008; Costanzo et al. 2009; Allegrezza et al. 2013) with F. sylvatica often limited to very steep, rocky slopes (Additional file 1: Figure S1). Moreover, the southern section of the group is largely deprived of forest cover which, even today, is intensively 
exploited for agricultural purpose at altitudes up to 1500 m a.s.l., i.e. Piano di Castelluccio, Norcia. These multiple lines of evidence suggest a pervasive negative impact of human activities such as agriculture and intensive grazing even at high elevations which may well have lowered the treeline in this group. The comparison between the Sibillini and Laga, a mountain group located less than $10 \mathrm{~km}$ south, is very informative. In central Italy, Laga had the highest average treeline $(1831 \mathrm{~m}$ a.s.l.), coupled with the lowest $\Delta$ maximum TLE - average TLE (192 $\mathrm{m}$ a.s.l.), showing a very limited variability of treeline elevation in this group (Additional file 1: Figure S1).

These results are the opposite of the Sibillini, although the two groups share similar climatic conditions. Our analysis suggests that the treeline position in the Laga group is explained by two factors: the bedrock type and the human population density around these mountains. Laga is the only group in central Italy with arenaceouspelitic flysch substrata, all other groups having limestone bedrock. A flysch substrate is much less permeable to rainfall than limestone, hence being able to retain large amounts of water in the soil and thus reducing summer drought (Gisotti 1983; Adamoli et al. 2012). As a result, trees are likely less affected by recurrent summer drought even at the treeline and in the southern faces of mountain peaks. Moreover, Laga had a very low past and present human density that, likely, do not provide a strong pressure on forests and, so, preserves an ample and continuous forest cover.

Gran Sasso and Velino-Sirente are two limestone groups with several high elevations and prominent peaks. Gran Sasso and Velino-Sirente also share low average treeline elevation with high values of $\Delta$ average TLE north - average TLE south. Indeed, the southern slopes of these mountains groups are almost devoid of forest cover with, for instance, the Campo Imperatore plateau (the largest in central Italy covering more than $75 \mathrm{~km}^{2}$ ) completely covered by grassland from $1600 \mathrm{~m}$ up to $2300 \mathrm{~m}$ a.s.l. (Additional file 1: Figure S1). Our PCA revealed that past human population is the most important explanatory variable for the low treeline elevation in the Gran Sasso group: both the groups have very large $(>50,000$ inhabitants) ancient cities dating back to Roman times, located just at the base of the southern face of the main peaks, i.e. L'Aquila for Gran Sasso and Avezzano for Velino-Sirente. Human exploitation of the latter area goes back to Roman times during which reclaimed a large plateau covered by a natural lake for agricultural purposes in Avezzano (Burri and Petitta 2004). Moreover, in these two groups the differences between mountain aspects become striking, with the north face often covered by $F$. sylvatica up to 1800-1900 m a.s.l., while south faces have treelines that in several cases lie below $1200 \mathrm{~m}$ a.s.l.
Bonanomi et al. (2018) first reported that F. sylvatica treeline elevation is lower on warmer, southern aspects compared to the colder north across the Apennines. This counterintuitive pattern, considering the current theory proposed to explain treeline elevation (Körner 2012), has been hypothesized to be the result of a combination between water shortage, and alteration of microclimate conditions when $F$. sylvatica cover is removed for pasturage. Allegrezza et al. (2016) reported that, at the treeline on south-facing mountain slopes, plants outside the canopy cover may experience very high soil and air temperatures (up to $38^{\circ} \mathrm{C}$ ) and intense summer drought which restricts $F$. sylvatica regeneration capability on open patches. In this regard, $F$. sylvatica itself can act as an ecosystem engineer by modifying forest microclimate thanks to its canopy cover and thus facilitating seedling establishment. Hence, we speculate that depression of treeline on southern mountain faces is due to the loss of engineering capability of $F$. sylvatica after canopy removal which, if intact, modulates a positive feedback on microclimate buffering temperature extremes, increasing soil and air moisture by limiting wind impact (Jones et al. 1997). Since self-shading buffers local microclimate, we hypothesize that this effect will be more important in southern than in northern aspects where air and soil temperature are already buffered by the reduced solar radiation. In this regards, intense anthropogenic disturbance could exacerbate the stressful impact of intense solar radiation, high daily temperature and summer drought on southerly exposed vegetation gaps, with negative effects on the capability of $F$. sylvatica to regenerate and recolonize the disturbed areas that rapidly become grassland. In this context, the VelinoSirente group had better represent this stressful ecological conditions for $F$. sylvatica treeline because combine a very high human pressure with the driest climate because of its position in the interior of the Italian peninsula (Pesaresi et al. 2017). Future work is needed to test this multifaceted hypothesis, comparing gap and closed forest microclimates in connection with ecophysiological studies that focus on the $F$. sylvatica regeneration niche (Grubb 1977) in northern and southern slopes expositions.

Majella is a large and compact massif composed of a high elevation plateau (average elevation $>2600 \mathrm{~m}$ a.s.l.), with steep and topographically complex external faces (Whitehead 1951). The Majella treeline shows large variability, with the highest absolute values in central Italy (2061 m a.s.l.) and five sites where the treeline exceeds $2000 \mathrm{~m}$ a.s.l. but, at the same time, several sites with a treeline below $1200 \mathrm{~m}$ a.s.l. (Additional file 1: Figure S1). The considerable variability observed in the treeline within the Majella cannot be explained by climatic factors but is likely the result of uneven past human 
activities, since large population inhabits Majella. Treelines appear especially depressed in close proximity to settlements and to external mountain faces that were more accessible for timber exploitation. In Majella, however, depressed treelines coexist with a very high treeline that only occurs in remote and almost inaccessible hanging valleys (Additional file 1: Figure S1), an observation that supports the human accessibility hypothesis. That said, the occurrence of several treelines at elevations $>2000 \mathrm{~m}$ a.s.l. on all mountain aspects, including the southern slopes, raises the ecological climatic potential of F. sylvatica.

The Marsicani mountain group has the most peaks (48 in our analysis), with many showing a large variability in treeline elevation. In three sites, absolute maximum treeline elevation exceeded $2000 \mathrm{~m}$ a.s.l. (i.e. Monte Greco, Terratta, and Monte Rotondo) and, in several cases, high and low treelines coexist within the same peaks (e.g. Monte Marsicano, La Meta). In this large and heterogeneous group, the treeline elevation is negatively associated with human population but positively with the minimum temperature of the coldest quarter of the year. Bonanomi et al. (2018) found that the winter climatic effect was stronger in high elevation peaks (> $1900 \mathrm{~m}$ a.s.l.), reporting for the first time that winter temperature affects $F$. sylvatica treeline elevation in addition to the well-known impact of MAT and growing season temperature (Körner and Paulsen 2004). In this regard, the Marsicani appears a complex group where climate mostly control treeline elevation in high elevation peak, while human disturbance seems more important in low elevation mountains. In addition, in the Marsicani group the past human pressure was likely uneven distributed also at low elevations because previous studies discovered the most ancient $F$. sylvatica old-growth forest of Europe in this geographical area (Piovesan et al. 2005).

\section{Southern Apennines}

The Picentini and Alburni-Cilento mountain groups in southern Italy have low elevation peaks, the highest point being Mt. Cervati (1899 m a.s.l.). In these groups, PCA indicates the importance of mountain peak elevation as a physical limiting factor for treeline elevation, given that the ecological potential of $F$. sylvatica is well above $2000 \mathrm{~m}$ a.s.l. at this latitude (Bonanomi et al. 2018). As a consequence, in several peaks F. sylvatica reaches the top of the mountain (e.g. Mts. Gelbison, Mercori, Panormo, Polveracchio), especially in the northern aspect. On the other hand, in these two groups with their low elevation peaks, the contribution of climatic factors to treeline elevation is of less importance.

Located at the southern limit of the carbonatic continental Apennines, the Pollino massif includes five peaks exceeding $>2150 \mathrm{~m}$ a.s.l. Average treeline elevation is high in Pollino, which comprises five sites with treelines higher than $2050 \mathrm{~m}$ a.s.l., including the highest site ever recorded for the continental distribution of $F$. sylvatica at $2141 \mathrm{~m}$ a.s.l. on Mt. Serra del Prete. Indeed, the latter site demonstrates that in southern Italy the climatic potential distribution is well above $2000 \mathrm{~m}$ a.s.l., probably lying around $2100 \mathrm{~m}$ a.s.l. Despite this, in many places treeline elevation in the Pollino group is very low (often lower than $1200 \mathrm{~m}$ a.s.l.), causing the large variability in treeline elevation observed in the group. Here, the occurrence of the highest treeline in a mountain group with relatively low elevation peaks could be explained by the co-existence of several sites that were little disturbed, if at all, by human activities and, on the other hand, by other peaks that were heavily exploited for timber and intensive grazing. Further studies are needed to explain the uneven treeline distribution in this mountain group.

Orsomarso, located a few kilometers to the west side of Pollino, shares a similar climate, being characterized by higher MAT and MTCQ than other groups located in the central and, especially, northern Apennines. In Orsomarso the treeline has a high average elevation but, unlike the nearby Pollino group, the lack of mountain peaks with elevation above $2000 \mathrm{~m}$ a.s.l. explains the absence of a very high treeline. By contrast, Orsomarso has very low values of $\Delta$ average TLE north - average TLE south and $\Delta$ maximum TLE - average TLE indexes, all proxies of limited anthropogenic disturbance. Unlike the Pollino massif, the Orsomarso group has a low population density and is physically isolated, with few mountain roads and several peaks that are quite difficult to reach even today. These factors support the poor accessibility hypothesis and may well explain the very extensive forest cover of this group as well as the poor variability of treeline elevation observed between contrasting mountain aspects.

\section{Conclusions}

Our survey of the F. sylvatica treeline along the Apennines revealed that treeline elevation is, on average, several hundred meters depressed in all the mountain groups analysed. We found evidence of a pervasive anthropogenic effect across the Apennines, with a strong impact in northern (i.e. Apuan Alps), central (Gran Sasso, Velino-Sirente, Sibillini) as well as in southern Apennines (i.e. Pollino). By contrast, the treeline elevation of some mountain groups (i.e. Laga, Simbruini, and Orsomarso) appears less negatively affected by past anthropogenic disturbances.

According with our expectations, treeline elevation was largely lower on warmer south-facing slopes, with values several hundred meters lower in Gran Sasso, Velino-Sirente, Matese, and Pollino. Although the causes 
of this pattern are still unknown, we argue that it could result from a combination of climatic constraints (e.g. summer drought) and human disturbance that, by causing to the loss of the microclimate buffer capability of $F$. sylvatica canopy may hamper tree seedling regeneration and open the way for secondary grassland colonization. Further studies are needed to test this hypothesis.

Finally, we found in the some groups of central (Majella and Marsicani) and southern Apennines (Pollino) the coexistence of a very depressed treeline with, a few kilometres apart, the highest treeline ever recorded for $F$. sylvatica. We explain this variability of treeline elevation with the co-existence, in the same mountain group, of very remote and almost inaccessible valleys with mountain slopes which, instead, were easily accessible and then extensively exploited for timber, charcoal production and grazing. In conclusion, our results show that the $F$. sylvatica treeline across the Apennines is shaped by the multifaceted interactions between climatic constraints (low winter temperature and low summer rainfall) and human disturbance, with their relative importance that depends on the mountain group and peak considered.

\section{Supplementary information}

Supplementary information accompanies this paper at https://doi.org/10. 1186/s40663-020-0217-8.

Additional file 1: Figure S1. Selected fifteen Apennine mountain groups. Panel A: hierarchical ordination of the Apennine mountain groups according to Euclidean distance calculated on geographical, demographic and climatic variables. Grey numbers in correspondence of the nodes report $p$ value, in bold significant differences. Panel B: geographical location of the mountain groups along the Apennine Fagus sylvatica range.

Additional file 2: Table S1. List of the 224 mountain peaks, distributed across the Apennines, where treeline boundaries were digitized, with mountain group, peak elevation, geographical coordinates, average peak elevation and substrates.

\section{Acknowledgements}

The authors thank the anonymous reviewers whose comments have greatly improved this manuscript. This work was partially supported by the PhD programme at the 'School of Agricultural and Food Sciences' granted to VM and $M Z$, in the Department of Agricultural Sciences, University of Naples Federico $\|$.

\section{Authors' contributions}

GB conceived the study; GB, GC, LS, MZ, AS and VM collected the data; AR, $M A, G T, A S, E A, L S, V M$ and $M Z$ analysed the data; GB and $E A$ wrote the main manuscript and coordinated the study. All authors contributed to discussing and interpreting the data at all stages. All authors read and approved the final manuscript.

\section{Funding}

Not applicable.

\section{Availability of data and materials}

Not applicable.

Ethics approval and consent to participate Not applicable.
Consent for publication

Not applicable.

\section{Competing interests}

The authors declare that they have no competing interests.

\section{Author details}

${ }^{1}$ Dipartimento di Agraria, Università di Napoli Federico II, via Università 100, 80055 Portici, NA, Italy. ${ }^{2}$ Scuola di Scienze Agrarie, Forestali, Alimentari e Ambientali, Università della Basilicata, Viale dell'Ateneo Lucano 10, 85100 Potenza, Italy. ${ }^{3}$ Dipartimento di Scienze Agrarie, Alimentari e Ambientali, Università Politecnica delle Marche, via Brecce Bianche, 60100 Ancona, Italy.

Received: 14 June 2019 Accepted: 21 January 2020

Published online: 29 January 2020

\section{References}

Adamoli L, Calamita F, Pizzi A (2012) Note Illustrative del Foglio 349 "G. Sasso" della Carta Geologica d'Italia alla scala 1:50.000. ISPRA, Rome

Allegrezza M, Ballelli S, Mentoni M, Olivieri M, Ottaviani C, Pesaresi S, Tesei G (2013) Biodiversity in the Sibillini Mountain range (Sibillini National Park, central Apennines): the example of Piè Vettore. Plant Sociol 50:57-89

Allegrezza M, Corti G, Cocco S, Pesaresi S, Chirico GB, Saracino A, Bonanomi G (2016) Microclimate buffering and fertility island formation during Juniperus communis ontogenesis modulate competition-facilitation balance. J Veg Sci 27:616-627

Allevato E, Saulino L, Cesarano G, Chirico GB, D'Urso G, Falanga Bolognesi S, Rita A, Rossi S, Saracino A, Bonanomi G (2019) Canopy damage by spring frost in European beech along the Apennines: effect of latitude, altitude and aspect. Remote Sens Environ 225:431-440

Almagià R (1959) L'Italia. UTET, Torino

Ameztegui A, Coll L, Brotons L, Ninot JM (2016) Land-use legacies rather than climate change are driving the recent upward shift of the mountain tree line in the Pyrenees. Glob Ecol Biogeogr 25:263-273

Barry RG (2008) Mountain weather and climate, 3rd edn. Cambridge University Press, Cambridge

Blasi C (2010) La vegetazione d'Italia con carte delle serie di vegetazione in scala 1:500.000. Palombi and Partner s.r.l. Editori, Rome

Bonanomi G, Rita A, Allevato E, Cesarano G, Saulino L, Di Pasquale G, Saracino A (2018) Anthropogenic and environmental factors affect the tree line position of Fagus sylvatica along the Apennines (Italy). J Biogeogr 45:2595-2608

Bruschi G, Criscuolo A, Paribeni E, Zanchetta G $(2004){ }^{14} \mathrm{C}$-dating from an old quarry waste dump of Carrara marble (Italy): evidence of pre-Roman exploitation. J Cult Herit 5:3-6

Burri E, Petitta M (2004) Agricultural changes affecting water availability: from abundance to scarcity (Fucino plain, Central Italy). Irrig Drain 53:287-299

Carmignani L, Conti P, Fantozzi PL, Mancini S, Massa G, Molli G, Vasselli L (2007) I marmi delle Alpi Apuane. Geoitalia 2:19-30

Catorci A, Ballelli S, Gatti R, Vitanzi A (2008) Studio fitosociologico delle praterie della Valle dell'Ambro (Parco Nazionale dei Monti Sibillini, Italia centrale). Informatore Botanico Italiano 40:193-241

Clarke KR, Gorley RN (2015) Getting started with PRIMER v7. PRIMER-E: Plymouth, Plymouth Marine Laboratory, Plymouth

Costanzo E, Furnari F, Tommaselli V (2009) A phytosociological survey of the main plant community types of alpine and sub-alpine belt in the Sibillini Mountains (central Apennines, Italy). Lazaroa 30:219-250

Di Pasquale G, Allevato E, Cocchiararo A, Moser D, Pacciarelli M, Saracino A (2014) Late Holocene persistence of Abies alba in low-mid altitude deciduous forests of central and southern Italy: new perspectives from charcoal data. $J$ Veg Sci 25:1299-1310

Fratianni S, Acquaotta F (2017) The climate of Italy. In: Soldati M, Marchetti M (eds) Landscapes and landforms of Italy. World Geomorphological Landscapes, Springer, Cham, pp 29-38

Gisotti P (1983) Geologia e pedologia nell'assetto del territorio. Edagricole, Bologna, p 209 ISBN:8820621851

Grubb PJ (1977) The maintenance of species-richness in plant communities: the importance of the regeneration niche. Biol Rev 52:107-145

Harsch MA, Hulme PE, McGlone MS, Duncan RP (2009) Are treelines advancing? A global meta-analysis of treeline response to climate warming. Ecol Lett 12:1040-1049 
Hijmans RJ, Cameron SE, Parra JL, Jones PG, Jarvis A (2005) Very high resolution interpolated climate surfaces for global land areas. Int J Climatol 25:1965-1978

Hofmann A (1991) II Faggio e le Faggete in Italia. Ministero dell' agricoltura e delle foreste, Rome

Jobbágy EG, Jackson RB (2000) Global controls of forest line elevation in the northern and southern hemispheres. Glob Ecol Biogeogr 9:253-268

Jones CG, Lawton JH, Shachak M (1997) Positive and negative effects of organisms as physical ecosystem engineers. Ecology 78:1946-1957

Körner C (1998) A re-assessment of high elevation treeline positions and their explanation. Oecologia 115:445-459

Körner C (2012) Alpine treelines: functional ecology of the global high elevation tree limits. Springer, Basel

Körner C, Paulsen J (2004) A world-wide study of high altitude treeline temperatures. J Biogeogr 31:713-732

Larcher W (1980) Physiological plant ecology. Springer-Verlag, Berlin-Heidelberg Legendre P, Legendre L (2012) Numerical ecology. 2nd English edition. Elsevier Science BV, Amsterdam

Macias-Fauria M, Johnson EA (2013) Warming-induced upslope advance of subalpine forest is severely limited by geomorphic processes. PNAS 110: 8117-8122

Magini E (1972) L'Abete rosso (Picea abies Karst) della Riserva Naturale di Campolino. Annali dell'Accademia Italiana di Scienze Forestali 21:287-321

Mancini NM, Mancini GM, Travaglini D, Nocentini S, Giannini R (2016) Prime osservazioni sulla struttura e la produzione di seme dei boschi cacuminali di faggio nei Monti della Laga. L'Italia Forestale e Montana 71:31-47

McNeill JR (2002) The mountains of the Mediterranean world. An environmental history. Cambridge University Press, Cambridge

Monteith JL, Unsworth M (2013) Principles of environmental physics: plants, animals, and the atmosphere, 4th edn. Academic Press, Oxford

Nolè A, Rita A, Ferrara AMS, Borghetti M (2018) Effects of a large-scale late spring frost on a beech (Fagus sylvatica $\mathrm{L}$.) dominated Mediterranean mountain forest derived from the spatio-temporal variations of NDVI. Ann For Sci 75:83

Packham JR, Thomas PA, Atkinson MD, Degen T (2012) Biological flora of the British Isles: Fagus sylvatica. J Ecol 100:1557-1608

Palombo C, Chirici G, Marchetti M, Tognetti R (2013) Is land abandonment affecting forest dynamics at high elevation in Mediterranean mountains more than climate change? Plant Biosyst 147:1-11

Pesaresi S, Biondi E, Casavecchia S (2017) Bioclimates of Italy. J Maps 13:955-960

Pezzi G, Ferrari C, Corazza M (2008) The altitudinal limit of beech woods in the northern Apennines (Italy). Its spatial pattern and some thermal inferences. Folia Geobot 43:447-459

Pignatti S (1998) I boschi d'Italia: sinecologia e biodiversità. Utet, Torino

Piovesan G, Di Filippo A, Alessandrini AEA, Biondi F, Schirone B (2005) Structure, dynamics and dendroecology of an old-growth Fagus forest in the Apennines. J Veg Sci 16:13-28

Piper Fl, Viñegla B, Linares JC, Camarero JJ, Cavieres LA, Fajardo A (2016) Mediterranean and temperate treelines are controlled by different environmental drivers. J Ecol 104:691-702

Randin CF, Paulsen J, Vitasse Y, Kollas C, Wohlgemuth T, Zimmermann NE, Körner C (2013) Do the elevational limits of deciduous tree species match their thermal latitudinal limits? Glob Ecol Biogeogr 22:913-923

Rita A, Gentilesca T, Ripullone F, Todaro L, Borghetti M (2014) Differential climategrowth relationships in Abies alba mill. And Fagus sylvatica $L$. in Mediterranean mountain forests. Dendrochronologia 32:220-229

Tinner W, Ammann B, Germann P (1996) Treeline fluctuations recorded for 12,500 years by soil profiles, pollen, and plant macrofossils in the central Swiss Alps. Arctic Alpine Res 28:131-147

Todaro L, Andreu L, D'Alessandro CM, Gutiérrez E, Cherubini P, Saracino A (2007) Response of Pinus leucodermis to climate and anthropogenic activity in the National Park of Pollino (Basilicata, Southern Italy). Biol Conserv 137:507-519

Vitali A, Urbinati C, Weisberg PJ, Urza AK, Garbarino M (2018) Effects of natural and anthropogenic drivers on land-cover change and treeline dynamics in the Apennines (Italy). J Veg Sci 29:189-199

Wang Y, Liang E, Sigdel S, Liu B, Camarero J (2017) The coupling of treeline elevation and temperature is mediated by non-thermal factors on the Tibetan plateau. Forests 8:109

Whitehead FH (1951) Ecology of the altipiano of Monte Maiella, Italy. J Ecol 39: 330-355

Wieser G, Tausz M (2007) Trees at their upper limit: treelife limitation at the alpine timberline, Vol 5. Springer, Dordrecht

\section{Submit your manuscript to a SpringerOpen ${ }^{\circ}$ journal and benefit from:}

- Convenient online submission

- Rigorous peer review

- Open access: articles freely available online

- High visibility within the field

- Retaining the copyright to your article

Submit your next manuscript at $\boldsymbol{\nabla}$ springeropen.com 